Volume 9, No.1.3, 2020

International Journal of Advanced Trends in Computer Science and Engineering

Available Online at http://www.warse.org/IJATCSE/static/pdf/file/ijatcse1291.32020.pdf

https://doi.org/10.30534/ijatcse/2020/1291.32020

\title{
Latency Issues in Internet of Things: A Review of Literature and Solution
}

\author{
Mohd Tamizan Abu Bakar ${ }^{1}$, Azrul Amri Jamal ${ }^{2}$ \\ ${ }^{1}$ University College TATI, Malaysia, tamizan@ tatiuc.edu.my \\ ${ }^{2}$ Universiti Sultan Zainal Abidin, Malaysia
}

\begin{abstract}
Currently the issues of latency in resource discovery is still being analyzed and verified. This paper offers a comparison of studies and solutions on the latency issues of the Internet of Things (IoT) in the resources discovery. The purpose is to review resources discovery in terms of how latency could be minimize or remove properly with different IoT solution. We compared and reviewed all latency related literature and solution of the IoT, categorizing all 32 research papers and related commercial results in two different comparison tables. Through this, we are able to provide a general view of the categories of latency, main objectives of the research, techniques, finding and solutions. It has also revealed any trends, gaps and opportunities for how the current IoT issues should be tackled when engaging with the IoT latency problems. Finally we hope this review can provides insight result for every IoT latency sources, suggesting suitable and relevance approaches that can be used to ensure a stable IoT resources discovery in future.
\end{abstract}

Key words: Internet of Things (IoT), Latency, Network Delay, Network Design, Resource Discovery.

\section{INTRODUCTION}

There are many definitions of Internet of Things (IoT) in literature by different researchers. Basically IoT is the fastest expending technologies all around us. With the development of Wireless Sensor Network (WSN), Radio Frequency Identification (RFID), cellular lines, Wi-Fi, Li-fi, sensor, Global Positioning System Satellite Network (GPS), Long-Range Wireless (LoRa) and other related techniques, IoT has been widely applied in many applications successfully and plays [1]. IoT helps individuals connect things to improve the quality of life. It also helps organizations and industries improve resource management to become more efficient. The IoT is helping industries, public and private sector organizations to increase operations efficiency. Academies and industries are now increasingly deploying IoT new solutions. Several innovation ideas have already appeared including narrow-band IoT (NB-IoT) [2] However, this rapid increase in growth has resulted issues of latency, security and new IoT challenges including how to combine the millions of IoT devices from different vendors using specialized applications and how to integrate new things into the existing network infrastructure [3].

According to Cisco System, in three years from now the IoT is expected to become a huge industry with more than 26 billion interconnected devices. Increased number of IoT appliances in daily networking environment results with huge data to manage in the big data area. Of course these traffics make many new IoT devices, applications, protocols, standard, architectures and models are being developed. The fog computing idea was introduced as a bridge between IoT and the cloud [4]. As summarized in Fig. 1, IoT can be divided into two different categories namely Industrial IoT and Massive IoT. Fog Computing is one of the new paradigms of cloud computing that brings several concepts of cloud services to the edge network environment to support it usage [5-9].

\section{CHALENGES IN IOT}

Today, IoT is the fastest growing technology around us because of the development of communication technologies such as RFID, WSN, LoRa, Wi-Fi, ZigBee, NFC, BLE, LTE, and SigFox. IoT devices are now entering the market using its own data transfer technique. Each of these communication technologies has its own unique and distinct advantages. Some researcher ideas have emerged including the NB-IoT and also the latest high-speed mobile IoTs such as 4G LTE and 5G. However, this rapid increase also introduces new IoT latency, security and challenges especially when it involves IIoT.

Challenges to IoT can be simplified into three different situations. First, the integration of IoT devices from different vendors each using different custom made applications, second the integration new IoT devices to the existing network infrastructure, and third the security of new IoT devices with varying levels of security configured. However, the rapid IoT growth has introduced new challenges, including platform selection matters. IoT platforms provide various capabilities in all environments. Various platforms in 
network communication will provide several options for IIoT to customize existing technologies with their features. We look forward to LoRa as the best option to support IIoT as some of the factors proposed by previous researchers $[10,11]$.

Until now, selecting the right IoT platform is the most challenging process for a company. These challenges include how to communicate millions of IoT devices from different vendors and how to integrate new thousands of IoT appliances into current network infrastructure. Selecting the right IoT platform for a given field of application is quiet challenging especially when selection from the mess of different platforms for massive IoT [12].

The implementation of IoT in cloud or fog computing is a difficult task when many parameters are required. IoT mobile cloud and fog research contributions are still limited but can provide a comprehensive overview of the IoT development including the status of the research related areas and help to settle uncover potential and importance research issues, including latency issues in IoT.

There are three IoT domains for long term research including infrastructure, nomadic users and digital economy, so a model for resilience IoT system was proposed to achieve research understanding in dependability, reliability, integrity, ability to fault-tolerant and availability of the IoTsystem [13]. All of the domain and objectives in the domain guiding us to face all challenges with different categories as below:

\subsection{Latency in IoT}

Network latency issues in IoT will happen when signal cannot be detected, but causes a delay in cloud environment. Many research papers already seem to have discussed the fundamental question of how much IoT network latency leak the information. For sure it is depends on network topologies such as latency in a star topology would leak no information about host's location and make much noise into the network [20].

\subsection{Bottlenecks (Delay) in IoT Technology}

Emerging applications that require ultra-low latencies can introduce new challenges beyond just latency requirements. Consider the application of manufacturing, which consists of thousands of sensors deployed within a factory. In such environments, even guaranteeing connectivity can be difficult. Moreover, many sensors are deployed in harsh environments that are highly reflective and absorptive in signal propagation, such as within a metal pipe or inside an injection molding machine. Finally, as nodes are not necessarily connected to power supplies, they need to be ultra-low-power, and may need to harvest energy from environments. This makes low-power communication a necessity in many cases. Also, local control and safety services come with high reliability and regular service requirements, in addition to ultra-low delays [42].

\subsection{Efficient IoT Sensing}

Today's sensing system has resulted in a large amount of sensor data beyond normal processing capabilities. But a new challenge for both academic research and industrial research are collecting, managing, and processing large IoT sensing data within an acceptable timeframe. When using the real-world IoT applications, the requirements of large size packets, extreme hassle, and high sensor data will bring new technical activities including resource discovery and real-time data managements (such as data collection, data storage, data organization, data analysis, and data publishing)[43] [47].

\subsection{IoT Robustness}

A robust IoT communication is a critical need for cyber-physical systems and applications. It is important for this application to have practical solutions to use multiple network interfaces, whether homogeneous or heterogeneous with the hope that the lost message probability can be reduced dramatically. Such configurations can be found in many recent application scenarios such as railway control systems, power grid control systems, and any emergency transmission systems [44].

\subsection{Energy Efficiency of IoT Equipment}

The energy efficiency of IoT equipment has been a growing concern for academic and industrial researchers. All parties are aware that there are many advantages of using green energy, but the disadvantages of the energy source are that energy conversion rates are low and closely related to current weather conditions, so they can be regarded as a very volatile energy generator [45].

\subsection{Security Issues}

IoT requires security, privacy and trust to ensure its credibility. Unsecured IoT risks or less secure may lead to problems such as unauthorized access, personal information disclosure, leakage of privacy data and data corruption. To date, IoT's safety has been gaining the attention of researchers and they continue to find new efficient techniques to expand. IoT securities issues can be categorized into five situations, confidentiality and authentication, access control, privacy, RFID security and secure routing. For sure, when increasing security issues will definitely increase latency [46].

\subsection{Emergence of Software Defined Network (SDN)}

The main challenge for Fog Computing is a flexible network architecture design which can be created through the paradigm of SDN. SDN is a new network approach aimed at segregating, designing, implementing and managing the network control plane. It will offer a new concepts of network control functionalities based on network abstraction and OTT are getting bigger and bigger bandwidth usage. [48]. 


\section{LATENCY ISSUES IN IOT}

Latency or also known as one-way delay refers to the amount of time for data to move from one point to one direction [50]. Level of latency can be identified with passive or active measurements [51]. As well as data usage in the other field, IoT data is collected from a variety of sources, whether wired or wireless networks like devices, sensors, and services. The IoT data from the various connected things are generated as data streams because the IoT data either structured or unstructured must be organized using the best real time resource discovering method. Refer to the idea of [53] the implementation of Breadth-First Search Technique (BFS) by implementing additional alpha multipliers, shows that it is an example of the most discovery methods and can increase its performances if any suitable element were added to the discovery processes.

Currently, there is an emergence of latency-sensitive and high-volume data in IoT applications, e.g., in the area of robotics, smart hospital, healthcare, smart city, smart vehicles, smart factory, agriculture industries or Industrial Internet of Things (IIoT). Such applications can be categorized as high-volume IoT and have strict latency requirements. The overall latency that goes directly between the two devices within the same network consists of four individual latencies. First; the software latency of the application, second; the software latency in the network application codes or networking stack, third; the hardware latency on media (wire or wireless), and forth; the hardware latency in network devices (access points, gateways, routers, switches, etc).

Hardware latency is relatively invariant or constant, but conversely, latency produced by software is very varied and thus difficult to measure in directly. However, the latency of the software introduced is important for sensitive-latency applications, especially point-to-point latency is the same as the total to all latencies between the two IoT nodes [24].Here, we try to evaluate the implementation of IoT latency, technology bottleneck and some of SDN solutions. Each solutions proposed was experimentally examine its latency performance for service composition in different fields especially in ubiquitous computing. The ability of IoT appliances to support high embeddedness and mobility are critical features for ubiquitous computing. To simplify the latency issue of ubiquitous computing in the IoT area, we should highlight the problem background in Figure 2.

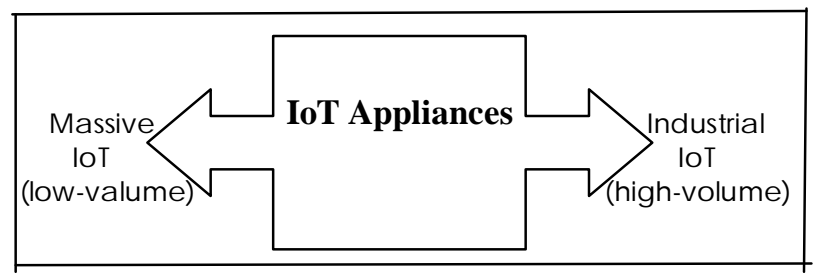

Figure 1: Categories of Basic IoT [4].

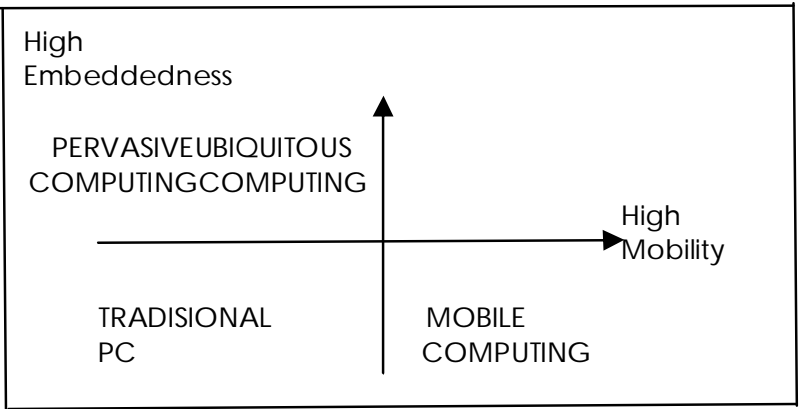

Figure 2: Relationship of Computing System Categories [24]

\section{IOT LATENCY SOLUTIONS REVIEW}

In this paper, we will discuss the findings in terms of solution either model, prototype or simulation for recovery the latency issues. Here we filtered 22 solutions (research paper 14 to 35) proposed to be reviewed. As a result, table 1 shows the comparison between several research papers in IoT latency solutions. In addition, we also reviewed IoT new products general products, especially in terms of IoT solutions such as QuickTalk - An Association-Free Communication Method for IoT [36], iCarMa - Inexpensive Cardiac Arrhythmia Management [37], Where's The Bear [38] - Automating Wildlife Image Processing Using IoT and Edge Cloud Systems, ParkMaster [39] - low-cost crowdsourcing architecture for evaluate parking availability in cities, Hadoop-Based Intelligent Care System (HICS) - healthcare system applications [40], and Secure Mobile Edge for Hajj [41].

Table 1: Comparison between IoT latency solutions

\begin{tabular}{|c|c|c|}
\hline $\begin{array}{c}\text { Research } \\
\text { Paper }\end{array}$ & Objective & Solution \\
\hline \multirow{7}{*}[14]{} & $\begin{array}{c}\text { To propose a new } \\
\text { mashup model, } \\
\text { known as the IoT } \\
\text { mashup that acts } \\
\text { as the composition } \\
\text { of the IoT source. }\end{array}$ & $\begin{array}{c}\text { Using the Big IoT } \\
\text { service which is part of } \\
\text { the big data services } \\
\text { where the results are } \\
\text { used to be explained in } \\
\text { turn as a managed } \\
\text { integration of various } \\
\text { types of data services. }\end{array}$ \\
\hline \multirow{7}{*}[15]{} & $\begin{array}{c}\text { To perform } \\
\text { latency-aware } \\
\text { techniques with } \\
\text { the goal of } \\
\text { resizing the size of } \\
\text { packets } \\
\text { transmission } \\
\text { depending on the } \\
\text { packet's incoming } \\
\text { rate. }\end{array}$ & $\begin{array}{c}\text { Using special } \\
\text { latency-aware software } \\
\text { approach for } \\
\text { performing packet } \\
\text { resizing process with it } \\
\text { objective to suite with } \\
\text { low-power embedded } \\
\text { platforms. }\end{array}$ \\
\hline \multirow{5}{*}[16]{} & $\begin{array}{c}\text { To reduce overall } \\
\text { network traffic } \\
\text { and minimizes } \\
\text { latency with } \\
\text { moving the }\end{array}$ & $\begin{array}{c}\text { The results showed this } \\
\text { approach uses virtual } \\
\text { resources in the mix of } \\
\text { some permission-based } \\
\text { block chains to provide }\end{array}$ \\
\hline
\end{tabular}




\begin{tabular}{|c|c|c|}
\hline & $\begin{array}{l}\text { components of } \\
\text { IoT from the } \\
\text { cloud onto simpler } \\
\text { and faster edge } \\
\text { hosts. }\end{array}$ & $\begin{array}{l}\text { IoT services on the } \\
\text { edge hosts, for example } \\
\text { using the software that } \\
\text { IoT components are } \\
\text { defined in the form of } \\
\text { virtual IoT sources. }\end{array}$ \\
\hline [17] & $\begin{array}{l}\text { To propose a new } \\
\text { modular } \\
\text { architecture for } \\
\text { the mobile host } \\
\text { that is meet } \\
\text { compliant and } \\
\text { fulfill the } \\
\text { architecture of } \\
\text { LTE system } \\
\text { requirements. }\end{array}$ & $\begin{array}{l}\text { The results proved the } \\
\text { advantages of } \\
\text { implementing the } \\
\text { mobile host in the } \\
\text { distributed network } \\
\text { with content caching } \\
\text { case can reduce level of } \\
\text { delay and improve } \\
\text { respond time more than } \\
90 \% \text {. }\end{array}$ \\
\hline [18] & $\begin{array}{l}\text { To produce low } \\
\text { latency VR/AR } \\
\text { because of } \\
\text { VR/AR is latency } \\
\text { sensitive. The } \\
\text { experiment results } \\
\text { in application of } \\
\text { round-trip latency } \\
\text { in the IoT network } \\
\text { should be short } \\
\text { and less than } 20 \\
\text { ms inside VR/AR } \\
\text { to make sure its } \\
\text { best quality in } \\
\text { vision } \\
\text { movements. }\end{array}$ & $\begin{array}{l}\text { The results showed the } \\
\text { Field Of View (FOV) in } \\
\text { VR/AR } 360^{\circ} \text { video } \\
\text { streaming is required in } \\
\text { performing solution at } \\
\text { the edge of a mobile } \\
\text { network are to optimize } \\
\text { the performance of } \\
\text { network bandwidth and } \\
\text { solve the latency issues. }\end{array}$ \\
\hline [19] & $\begin{array}{c}\text { To propose a } \\
\text { methodology that } \\
\text { can arrange server } \\
\text { management } \\
\text { concept to } \\
\text { minimize latency } \\
\text { and maximize } \\
\text { server utilization. }\end{array}$ & $\begin{array}{l}\text { Both of short latency } \\
\text { and very high server } \\
\text { utilization can be } \\
\text { achieved by using this } \\
\text { methodology based on } \\
\text { different peak loads for } \\
\text { different cells. }\end{array}$ \\
\hline [20] & $\begin{array}{c}\text { To design } \\
\text { low-latency } \\
\text { anonymity } \\
\text { schemes and at the } \\
\text { same time provide } \\
\text { protection to the } \\
\text { network by } \\
\text { observing } \\
\text { malicious servers } \\
\text { capable of acting } \\
\text { as local hackers } \\
\text { who are able to } \\
\text { see latency of } \\
\text { connection } \\
\text { networks created } \\
\text { via the Tor circuit. }\end{array}$ & $\begin{array}{l}\text { The results showed it } \\
\text { can help to reduce the } \\
\text { respond time based on } \\
\text { average RTT circuit, } \\
\text { prevent some of the } \\
\text { latency-based attacks, } \\
\text { and improve } \\
\text { low-latency anonymity } \\
\text { schemes efficiency } \\
\text { using Tor path selection } \\
\text { with latency-aware } \\
\text { algorithm. }\end{array}$ \\
\hline [21] & $\begin{array}{l}\text { To do experiment } \\
\text { for semantic } \\
\text { reasoning at edge }\end{array}$ & $\begin{array}{l}\text { Experimental results } \\
\text { show that edge } \\
\text { reasoning can reduce }\end{array}$ \\
\hline
\end{tabular}

\begin{tabular}{|c|c|c|}
\hline & $\begin{array}{c}\text { nodes by } \\
\text { performing } \\
\text { latency and } \\
\text { scalability } \\
\text { analysis in smart } \\
\text { city scenarios. }\end{array}$ & $\begin{array}{l}\text { the usage of network } \\
\text { bandwidth and reduce } \\
\text { the level of latency. }\end{array}$ \\
\hline [22] & $\begin{array}{l}\text { To measure the } \\
\text { level of the } \\
\text { latency between } \\
\text { Tor nodes } \\
\text { especially from a } \\
\text { point of view that } \\
\text { uses Ting } \\
\text { techniques. }\end{array}$ & $\begin{array}{l}\text { The results showed that } \\
\text { Ting technique is } \\
\text { accurate. The } \\
\text { measurements are } \\
\text { stable over time, } \\
\text { latency data sets that } \\
\text { allow Ting to be used in } \\
\text { different ways, } \\
\text { including faster } \\
\text { methods to modify } \\
\text { Tor's circuit and } \\
\text { efficient long circuit } \\
\text { with low point-to-point } \\
\text { latency. }\end{array}$ \\
\hline [23] & $\begin{array}{c}\text { To propose } \\
\text { service abstraction } \\
\text { framework named } \\
\text { as ACACIA, } \\
\text { which enables to } \\
\text { perform CI } \\
\text { applications on } \\
\text { edge clouds in } \\
\text { mobile networks. }\end{array}$ & $\begin{array}{l}\text { When compared with } \\
\text { existing cloud and } \\
\text { mobile solutions, } \\
\text { results of this } \\
\text { implementation shows } \\
\text { that ACACIA holistic } \\
\text { approach provides a } \\
70 \% \text { reduction of the } \\
\text { application latency } \\
\text { level. }\end{array}$ \\
\hline [24] & $\begin{array}{l}\text { To solve the } \\
\text { critical issue of } \\
\text { latency in the } \\
\text { usage of wakeup } \\
\text { receiver (WuRx). } \\
\text { This approach is } \\
\text { widely used when } \\
\text { the remote sensor } \\
\text { receivers need to } \\
\text { be constant or } \\
\text { often to meet } \\
\text { latency } \\
\text { requirements. }\end{array}$ & $\begin{array}{l}\text { The results showed that } \\
\text { it can be produced very } \\
\text { attractive for } \\
\text { short-range } \\
\text { latency-critical IoT } \\
\text { application while } \\
\text { maintaining low } \\
\text { latency outputs and } \\
\text { concurrently it worked } \\
\text { properly using } \\
\text { fully-integrated wakeup } \\
\text { receiver. }\end{array}$ \\
\hline [25] & $\begin{array}{l}\text { To propose a new } \\
\text { latency solution at } \\
\text { the gateway node } \\
\text { named as } \\
\text { reply-cache } \\
\text { mechanism. }\end{array}$ & $\begin{array}{l}\text { The results showed the } \\
\text { improvement of latency } \\
\text { management in E2E is } \\
\text { around } 78.37 \% \text { and } \\
\text { delay arrangement at } \\
\text { the gateway node } \\
\text { within } 41.17 \% \text { of } \\
\text { energy savings. }\end{array}$ \\
\hline [26] & $\begin{array}{c}\text { To propose a new } \\
\text { solution based on } \\
\text { dynamic resource } \\
\text { reservation } \\
\text { scheme using an } \\
\text { air-interface slice } \\
\text { in arrangement } \\
\text { large number of }\end{array}$ & $\begin{array}{l}\text { The results showed that } \\
\text { it can achieve the main } \\
\text { objectives to reduce the } \\
\text { latency rate of } \\
\text { air-interface and the } \\
\text { drop packets. Their } \\
\text { objectives can be } \\
\text { achieved using the right }\end{array}$ \\
\hline
\end{tabular}




\begin{tabular}{|c|c|c|}
\hline & $\begin{array}{l}\text { sensors to support } \\
\text { emergency flow in } \\
\text { cellular networks. }\end{array}$ & $\begin{array}{l}\text { scheme that allows } \\
\text { ultralow latency flow to } \\
\text { be transported securely } \\
\text { by guaranteed radio } \\
\text { link connections. }\end{array}$ \\
\hline [27] & $\begin{array}{l}\text { To propose an } \\
\text { approach to } \\
\text { estimate the } \\
\text { latency of } \\
\text { computer } \\
\text { networking } \\
\text { software in each } \\
\text { individual device } \\
\text { without the use of } \\
\text { specific and } \\
\text { precise hardware } \\
\text { to estimate latency } \\
\text { in the networking } \\
\text { software, bases on } \\
\text { a rounded time } \\
\text { measurement } \\
\text { between multiple } \\
\text { devices. }\end{array}$ & $\begin{array}{l}\text { Not using special } \\
\text { hardware, the results } \\
\text { show the approach } \\
\text { offers best results in } \\
\text { terms of scalability if } \\
\text { the time in latency } \\
\text { distribution latency can } \\
\text { be assumed. Otherwise, } \\
\text { the determination of } \\
\text { latency is impossible. }\end{array}$ \\
\hline [28] & $\begin{array}{l}\text { To prove the } \\
\text { evidence of how } \\
\text { by using wake-up } \\
\text { radios we can } \\
\text { abate the data } \\
\text { latency imposed } \\
\text { by Low Power } \\
\text { Listening (LPL) } \\
\text { dramatically. }\end{array}$ & $\begin{array}{l}\text { The results showed all } \\
\text { parameters that } \\
\text { operating at a different } \\
\text { frequency than the main } \\
\text { radio were investigated } \\
\text { including the use of } \\
\text { wake-up radios } \\
\text { additional low-cost and } \\
\text { ultra-low power radios. }\end{array}$ \\
\hline [29] & $\begin{array}{l}\text { To produce an } \\
\text { approach for } \\
\text { effective } \\
\text { monitoring of the } \\
5 \mathrm{G} \text { mobile } \\
\text { network software } \\
\text { defined using an } \\
\text { IoT-based } \\
\text { framework. }\end{array}$ & $\begin{array}{l}\text { To results showed a } \\
\text { framework that gives } \\
\text { much better } \\
\text { implementation to } \\
\text { monitor the mobile } \\
\text { network operators } \\
\text { system for utilizing the } \\
\text { MQTT a unified IoT } \\
\text { protocol which is light, } \\
\text { data-agnostic, and } \\
\text { interoperable. }\end{array}$ \\
\hline [30] & $\begin{array}{l}\text { To evaluate level } \\
\text { of latency in a } \\
\text { native-IP wireless } \\
\text { communication } \\
\text { network for } \\
\text { building } \\
\text { automation (BA) } \\
\text { system with real } \\
\text { experimental. } \\
\end{array}$ & $\begin{array}{l}\text { The results showed that } \\
\text { the default CoAP } \\
\text { retransmission timeout } \\
\text { (RTO) is not optimal } \\
\text { will degrades the } \\
\text { performance of latency } \\
\text { and leads to a "Stair } \\
\text { Effect". }\end{array}$ \\
\hline [31] & $\begin{array}{l}\text { To propose a new } \\
\text { protocol translator } \\
\text { for the IoT that } \\
\text { will aim at the } \\
\text { inspections of } \\
\text { Internet } \\
\text { protocol-based }\end{array}$ & $\begin{array}{l}\text { The result shows that } \\
\text { the proposed protocol is } \\
\text { not a middleware and } \\
\text { has its own advantages } \\
\text { ie; no design time } \\
\text { dependency, } \\
\text { transparent, low }\end{array}$ \\
\hline
\end{tabular}

\begin{tabular}{|c|c|c|}
\hline & $\begin{array}{l}\text { communication } \\
\text { protocols to be } \\
\text { met the IoT } \\
\text { protocol } \\
\text { inter-operability, } \\
\text { security, and } \\
\text { transparency. }\end{array}$ & $\begin{array}{c}\text { latency, secured } \\
\text { through authorization } \\
\text { and authentication, and } \\
\text { used on-demand } \\
\text { protocols. }\end{array}$ \\
\hline [32] & $\begin{array}{c}\text { To use an } \\
\text { approach that } \\
\text { extends } \\
\text { extensively } \\
\text { current IoT } \\
\text { protocol to } \\
\text { support channel } \\
\text { aggregation, to } \\
\text { ensure low latency } \\
\text { service for critical } \\
\text { tasks within the } \\
\text { IoT network and } \\
\text { to improve data } \\
\text { transmission rates } \\
\text { for critical tasks } \\
\text { via simultaneous } \\
\text { multiple } \\
\text { deliveries. }\end{array}$ & $\begin{array}{l}\text { The results show that } \\
\text { the chosen approach } \\
\text { reduces the latency of } \\
\text { critical tasks is better } \\
\text { than traditional } \\
\text { approaches and } \\
\text { perform optimum relay } \\
\text { configurations that } \\
\text { minimize the uploaded } \\
\text { latency can be obtained } \\
\text { within polynomial time. }\end{array}$ \\
\hline [33] & $\begin{array}{l}\text { To solve problems } \\
\text { depends on cloud } \\
\text { computing by } \\
\text { using distributed } \\
\text { cloud service } \\
\text { concepts or } \\
\text { mobile edge } \\
\text { computing in 5G } \\
\text { networks due to } \\
\text { the } \\
\text { communication } \\
\text { latency related to } \\
\text { physical location } \\
\text { of the cloud server } \\
\text { away from mobile } \\
\text { users }\end{array}$ & $\begin{array}{l}\text { The results show that } \\
\text { permissive has good } \\
\text { performance while tight } \\
\text { systems become } \\
\text { degraded when it } \\
\text { includes latency of } \\
\text { controller } \\
\text { communications in the } \\
\text { system, but the } \\
\text { underestimation system } \\
\text { that selects the } \\
\text { destination with the } \\
\text { lowest latency policies } \\
\text { will result in some } \\
\text { errors. }\end{array}$ \\
\hline [34] & $\begin{array}{l}\text { To investigate the } \\
\text { model of MAC } \\
\text { latency based on } \\
\text { mathematical } \\
\text { queue theory for } \\
\text { MAC slotted } \\
\text { superframe } \\
\text { structure and to } \\
\text { study level of } \\
\text { simplicity the } \\
\text { software tools } \\
\text { based on packet } \\
\text { ranking } \\
\text { simulation results. }\end{array}$ & $\begin{array}{l}\text { The results indicate that } \\
\text { the proposed method } \\
\text { can reduce the MAC } \\
\text { access latency while } \\
\text { meet up the packet } \\
\text { generation rates, the } \\
\text { number of nodes in the } \\
\text { network, and the packet } \\
\text { length of each node. }\end{array}$ \\
\hline [35] & $\begin{array}{l}\text { To measure } \\
\text { latency rate for } \\
\text { real time IoT } \\
\text { appliances and }\end{array}$ & $\begin{array}{l}\text { The result shows that } \\
\text { the mechanical scan } \\
\text { antenna improves } \\
\text { overall system latency }\end{array}$ \\
\hline
\end{tabular}




\begin{tabular}{|c|c|}
\hline $\begin{array}{c}\text { quality of internet } \\
\text { access based on } \\
\text { the performance } \\
\text { metrics such as } \\
\text { scanning rate of } \\
\text { the mechanically } \\
\text { and electronically } \\
\text { steered antennas. }\end{array}$ & $\begin{array}{c}\text { due to the time of } \\
\text { sliding needed to } \\
\text { position from one } \\
\text { satellite to another. }\end{array}$ \\
\hline
\end{tabular}

\section{THE IMPORTANCE OF IOT LATENCY SOLUTIONS}

One of the main targets for $5 \mathrm{G}$ is to enable IoT critical latency applications. [52]. In the future, we believe that the existence of an IoT environment that requires a small or short period latency will increase. In short, this paper filtered the latency issues in transferring data from the various area of studies from hardware to software. One of the added values of this paper is to consider any missing latency scenario to be evaluated in the future of IoT experiments. As a benchmark, the communication roundtrip latency of industrial IoT applications can be less than $300 \mathrm{~ms}$ between countries in the different continents and less than $50 \mathrm{~ms}$ between countries in the same continent [49]. For example, some ideas that are widespread in the wired network environment seem to be reasonable to measure the network bandwidth delays. Someone can add a timestamp for each packet before it is being shipped and subtract receipt from delivery time or using Time Trip Round (RTT) probe packet divided by two as a one-way counting. If any timestamps can be added in one pack directly before it is being sent, this method allows us to determine packet delays to be smooth and correct without contingency overhead. [51-54]. To see large variation changes will be highlighted, table 2 shows that every solutions can be classified into four categories of findings, and specifically in the result they are grouped into different types of latency.

Table 2: Area of Studies and Issues to be Further Explored

\begin{tabular}{|c|c|c|}
\hline $\begin{array}{c}\text { Group of } \\
\text { Research }\end{array}$ & Finding & Result \\
\hline$[14][16]$ & $\begin{array}{c}\text { Solve latency issues } \\
\text { using application or } \\
\text { SDN components. }\end{array}$ & $\begin{array}{c}\text { The edge processing } \\
\text { technology produce is } \\
\text { suitable to determine } \\
\text { the software latency } \\
\text { in the network } \\
\text { application code or } \\
\text { networking stack. }\end{array}$ \\
\hline $\begin{array}{c}\text { S18] } \\
{[24][26]}\end{array}$ & $\begin{array}{c}\text { Solve latency issues } \\
\text { using new } \\
\text { architecture } \\
\text { (28] [35] }\end{array}$ & $\begin{array}{c}\text { Several enables } \\
\text { processing } \\
\text { technologies suitable } \\
\text { to determine the } \\
\text { ordware/sensor) }\end{array}$ \\
\hline $\begin{array}{c}\text { hardware latency on } \\
\text { media. }\end{array}$ \\
$\begin{array}{c}\text { [25] [19] [27] } \\
{[32][33]} \\
{[34]}\end{array}$ & $\begin{array}{c}\text { Solve latency issues } \\
\text { using latency-aware } \\
\text { algorithm, model or } \\
\text { technique test by } \\
\text { simulator. }\end{array}$ & $\begin{array}{c}\text { Determining the } \\
\text { round-trip time } \\
\text { between pair suitable } \\
\text { to determine the } \\
\text { software latency of } \\
\text { the application. }\end{array}$ \\
\hline
\end{tabular}

\begin{tabular}{|c|c|c|}
\hline [29] [30] & $\begin{array}{c}\text { Several experiments } \\
\text { focusing on } \\
\text { Solve latency issues } \\
\text { comparing latency of } \\
\text { different network } \\
\text { of standard. } \\
\text { topology is suitable to } \\
\text { determine the } \\
\text { hardware latency on } \\
\text { media. }\end{array}$ \\
\hline
\end{tabular}

\section{CONCLUSION}

The objective for low latency in IoT resource discovery cannot be achieved by improving only one part of issues or designs. Today we need to think about the future of IoT networks that will be based on some special elements such as SDN to centralize and facilitate the control of the network, NFV to enable flexible and scalable architecture that can be tailored to the needs of some used cases on the same IoT infrastructure, and as well as it can benefits from the local computational power provided by applications running in the mobile edge cloud. Based on this study, all new solutions to determine hardware latency in the IoT network devices and software latency caused by resource discovery factors need to be analyzed.

\section{ACKNOWLEDGEMENT}

We are fully acknowledged TATI University College and University of Sultan Zainal Abidin as our employer and sponsor.

\section{REFERENCES}

1. Ma, Y., Rao, J., Hu, W., Meng, X., Han, X., Zhang, Y.,Liu, C. (2012). An efficient index for massive IOT data in cloud environment. Proceedings of the 21st ACM International Conference on Information and Knowledge Management - CIKM '12, 2129. https://doi.org/10.1145/2396761.2398587

2. Miao, Y., Li, W., Tian, D., Hossain, M. S., \& ... (2017). Narrow Band Internet of Things: Simulation and Modelling. IEEE Internet of Things ..., 2, 20557-20577. Retrieved from http://ieeexplore.iee.org/abstract/document/8010279/

3. Koreshoff, T. L., Robertson, T., \& Leong, T. W. (2013). Internet of Things: a review of literature and products, 335-344.

4. Syed, M. H., Fernandez, E. B., \& Ilyas, M. (2016). A Pattern for Fog Computing. Proceedings of the 10th Travelling Conference on Pattern Languages of Programs - VikingPLoP '16, 1-10. https://doi.org/10.1145/3022636.3022649

5. Ketel, M. (2017). Fog-Cloud Services for IoT. Proceedings of the SouthEast Conference on - ACM SE '17, 262-264. https://doi.org/10.1145/3077286.3077314

6. Aa Yi, S., Li, C., \& Li, Q. (2015). A Survey of Fog Computing. Proceedings of the 2015 Workshop on Mobile Big Data - Mobidata '15, 37-42. https://doi.org/10.1145/2757384.2757397 
7. Bonomi, F., Milito, R., Zhu, J., \& Addepalli, S. (2012). Fog Computing and Its Role in the Internet of Things. Proceedings of the First Edition of the MCC Workshop on Mobile Cloud Computing, 13-16. https://doi.org/10.1145/2342509.2342513

8. Xue, Y., Li, J., Nazarian, S., \& Bogdan, P. (2017). Fundamental Challenges Toward Making the IoT a Reachable Reality. ACM Transactions on Design Automation of Electronic Systems, 22(3), 1-25. https://doi.org/10.1145/3001934

9. Shi, Y., Ding, G., Wang, H., Roman, H. E., \& Lu, S. (2015). The fog computing service for healthcare. 2015 2nd International Symposium on Future Information and Communication Technologies for Ubiquitous HealthCare (Ubi-HealthTech), 1-5. https://doi.org/10.1109/Ubi-HealthTech.2015.7203325

10. Hossain, T., Doi, Y., Tazin, T., Ahad, M. A. R., \& Inoue, S. (2018). Study of LoRaWAN Technology for Activity Recognition. Proceedings of the 2018 \{ACM International Joint Conference and 2018 International Symposium on Pervasive and Ubiquitous Computing and Wearable Computers, UbiComp/ISWC 2018 Adjunct, Singapore, October 08-12, 2018, 1449-1453. https://doi.org/10.1145/3267305.3267510

11. Rahman, A., \& Suryanegara, M. (2017). The development of IoT LoRa: A performance evaluation on LoS and Non-LoS environment at $915 \mathrm{MHz}$ ISM frequency. Proceedings - International Conference on Signals and Systems, ICSigSys 2017, 163-167. https://doi.org/10.1109/ICSIGSYS.2017.7967033

12. Hejazi, H., Rajab, H., Cinkler, T., \& Lengyel, L. (2018). Survey of platforms for massive IoT. 2018 IEEE International Conference on Future IoT Technologies, Future IoT 2018, 2018-Janua, 1-8. https://doi.org/10.1109/FIOT.2018.8325598

13. Delik, K. A. (2015). The Internet of Things. Ubiquity, 291(July 2012), 1-40. https://doi.org/10.5480/1536-5026-34.1.63

14. Boulakbech, M., Messai, N., Sam, Y., Devogele, T., \& Hammoudeh, M. (2017). IoT Mashups: from IoT Big Data to IoT Big Service Marwa. Proceedings of the International Conference on Future Networks and Distributed Systems - ICFNDS '17, 20. https://doi.org/10.1145/3102304.3102324

15. Maghazeh, A., Bordoloi, U. D., Dastgeer, U., Andrei, A., Eles, P., \& Peng, Z. (2017). Latency-Aware Packet Processing on CPU-GPU Heterogeneous Systems. Proceedings of the 54th Annual Design Automation Conference 2017 on - DAC '17, 1-6. https://doi.org/10.1145/3061639.3062269

16. Samaniego, M., \& Deters, R. (2016). Using Blockchain to push Software-Defined IoT Components onto Edge Hosts. Proceedings of the International Conference on Big Data and Advanced Wireless Technologies - BDAW '16, 1-9. https://doi.org/10.1145/3010089.3016027

17. Chang, C., Alexandris, K., \& Nikaein, N. (n.d.). MEC Architectural Implications for LTE / LTE-A Networks. MobiArch'16, October 03-07, 2016, New York City, NY, USA ?2016, 13-18.
18. Mangiante, S., Klas, G., Navon, A., GuanHua, Z., Ran, J., \& Silva, M. D. (2017). VR is on the Edge: How to Deliver $360^{\circ}$ Videos in Mobile Networks Simone. Proceedings of the Workshop on Virtual Reality and Augmented Reality Network - VR/AR Network '17, 30-35. https://doi.org/10.1145/3097895.3097901

19. Politecnico, F. M., Torino, D., Kirkpatrick, I. S., \& Chiasserini, C.-F. (2016). How Close to the Edge? Delay/Utilization Trends in MEC. CAN'16, December 12 2016, Irvine, CA, USA ?2016, 37-42. https://doi.org/10.1145/3010079.3010080

20. Hopper, N., Vasserman, E. Y., \& Chan-TIN, E. (2010). How much anonymity does network latency leak? ACM Transactions on Information and System Security, 13(2), 1-28. https://doi.org/10.1145/1698750.1698753

21. Su, X., Li, P., Li, Y., Flores, H., Riekki, J., \& Prehofer, C. (2016). Towards Semantic Reasoning on the Edge of IoT SystemsInteractive Collaborative Robotics. IEEE Communications Magazine, 54(3), 63-68. https://doi.org/10.1007/978-3-319-43955-6

22. Cangialosi, F., Levin, D., \& Spring, N. (2015). Ting: Measuring and Exploiting Latencies Between All Tor Nodes. Proceedings of the 2015 ACM Conference on Internet Measurement Conference - IMC '15, 289-302. https://doi.org/10.1145/2815675.2815701

23. Cho, J., Sundaresan, K., Mahindra, R., Van Der Merwe, J., \& Rangarajan, S. (2016). Demo: ACACIA Context-aware edge computing for continuous interactive applications over mobile networks. 22nd Annual International Conference on Mobile Computing and Networking, MobiCom 2016, (CONFCODENUMBER), 505-506. https://doi.org/10.1145/2973750.2985623

24. Ding, M., Zhang, P., Lu, C., Zhang, Y., Traferro, S., Schaik, G. Van, ... Philips, K. (2017). A $2.4 \mathrm{GHz}$ BLE-Compliant Fully-Integrated Wakeup Receiver for Latency-Critical IoT applications using a 2-Dimensional Wakeup Pattern in 90nm CMOS. EEE Internet of Things Journal, 168-171.

25. Reddy, Y. S., \& Pattanaik, K. K. (2017). A reply cache mechanism to reduce query latency of WSN in IoT sensory environment. Proceedings - 2016 IEEE International Symposium on Nanoelectronic and Information Systems, INIS 2016, 38-42. https://doi.org/10.1109/iNIS.2016.020

26. Sun, G., Wang, G., \& Liu, G. (2016). Air-Interface Slice Based Dynamic Resource Reservation for Ultra-Low-Latency IoT Transmissions. Proceedings Conference on Local Computer Networks, LCN, 603-606. https://doi.org/10.1109/LCN.2016.102

27. Puttnies, H., Konieczek, B., Heller, J., Timmermann, D., \& Danielis, P. (2016). Algorithmic approach to estimate variant software latencies for latency-sensitive networking. 7th IEEE Annual Information Technology, Electronics and Mobile Communication Conference, IEEE IEMCON 2016. https://doi.org/10.1109/IEMCON.2016.7746281

28. Basagni, S. (2017). Demo Abstract: Abating LPL-induced Latency with Wake-up Radio Technology. Proceed- Ings of The 2nd ACM/IEEE International 
Conference on Internet-of-Things Design and Implementation, Pittsburgh, PA USA, April 2017 (IoTDI 2017), 303-304.

https://doi.org/10.1145/3054977.3057322

29. Seilbagger, H. D. (2017). An IoT based Monitoring Framework for Software Defined 5G Mobile Networks, $7-10$.

30. Zhu, H., Pang, Z., Xie, B., \& Bag, G. (2016). IETF IoT based wireless communication for latency-sensitive use cases in building automation. IEEE International Symposium on Industrial Electronics, 2016-Novem, 1168-1173. https://doi.org/10.1109/ISIE.2016.7745060

31. Derhamy, H., Eliasson, J., \& Delsing, J. (2017). IoT Interoperability - On-demand and low latency Transparent Multi-protocol Translator. IEEE Internet of Things Journal, 4(5), 1-1. https://doi.org/10.1109/JIOT.2017.2697718

32. Hsu, S. H., Lin, C. H., Wang, C. Y., \& Chen, W. T. (2017). Minimizing upload latency for critical tasks in cellular-based IoT networks using multiple relays. IEEE International Conference on Communications. https://doi.org/10.1109/ICC.2017.7997421

33. Intharawijitr, K., Iida, K., Koga, H., \& Yamaoka, K. (2017). Practical Enhancement and Evaluation of a Low-Latency Network Model Using Mobile Edge Computing. 2017 IEEE 41st Annual Computer Software and Applications Conference (COMPSAC), 567-574. https://doi.org/10.1109/COMPSAC.2017.190

34. Yan, H., Zhang, Y., Pang, Z., \& Xu, L. Da. (2014). Superframe planning and access latency of slotted MAC for industrial WSN in IoT environment. IEEE Transactions on Industrial Informatics, 10(2), 1242-1251. https://doi.org/10.1109/TII.2014.2306776

35. Sturdivant, R., \& Chong, E. K. P. (2017). System Latency Performance of Mechanical and Electronic Scanned Antennas for LEO Ground Stations for IoT and Internet Access, 36-39.

36. Ham, S., Lee, J., \& Lee, K. (2017). QuickTalk: An Association-Free Communication Method for IoT Devices in Proximity. ACM. https://doi.org/10.1145/3130921

37. Puri, C., Ukil, A., Bandyopadhyay, S., Singh, R., Pal, A., \& Mandana, K. (2016). iCarMa: Inexpensive Cardiac Arrhythmia Management - An IoT Healthcare Analytics Solution. Proceedings of the First Workshop on IoT-Enabled Healthcare and Wellness Technologies and Systems - IoT of Health '16, 3-8. https://doi.org/10.1145/2933566.2933567

38. Elias, A. R., Golubovic, N., Krintz, C., \& Wolski, R. (2017). Where's The Bear? Automating Wildlife Image Processing Using IoT and Edge Cloud Systems Andy. Proceedings of the Second International Conference on Internet-of-Things Design and Implementation - IoTDI '17, 247-258. https://doi.org/10.1145/3054977.3054986

39. Grassi, G., Sammarco, M., Bahl, P., Jamieson, K., \& Pau, G. (2015). Poster: ParkMaster: Leveraging Edge Computing in Visual Analytics. Proceedings of the 21st Annual International Conference on Mobile Computing and Networking, 257-259. https://doi.org/10.1145/2789168.2795174
40. Rathore, M. M., Paul, A., Ahmad, A., Anisetti, M., \& Jeon, G. (2017). Hadoop-Based Intelligent Care System (HICS). ACM Transactions on Internet Technology, 18(1), 1-24. https://doi.org/10.1145/3108936

41. Rahman, A., \& Hassanain, E. (2017). Towards a Secure Mobile Edge Computing Framework for Hajj. EEE Internet of Things Journal, 5.

42. Foundation, N. S., Foundation, N. S., \& Foundation, N. S. (2016). NSF Follow-on Workshop on Ultra-Low Latency Wireless Networks. REPORT, (1448360).

43. Yang, B. C., Puthal, D., Mohanty, S. P., \& Kougianos, E. (2017). Big-Sensing-Data Curation for the Cloud Is Coming. IEEE CONSUMER ELECTRONICS MAGAZINE, (october).

44. Shih, C.-S., \& Yeh, Z.-Y. (2016). Goodput Optimization for Multiple-Path IoT Robust Messaging. Proceedings of the International Conference on Research in Adaptive and Convergent Systems - RACS '16, 109-116. https://doi.org/10.1145/2987386.2987403

45. Nan, Y., Li, W., Bao, W., Delicato, F. C., Pires, P. F., Dou, Y., \& Zomaya, A. Y. (2017). Adaptive Energy-aware Computation Offloading for Cloud of Things Systems. IEEE Access, $\mathrm{XXX}(\mathrm{X}), 1-1$. https://doi.org/10.1109/ACCESS.2017.2766165

46. Punia, A. (2017). A Perspective on Available Security Techniques in IoT. IEEE International Conference On Recent Trends in Electronics Information \& Communication Technology (RTEICT), May 19-20, 2017, India A, 1553-1559.

47. Bisdikian, C., Kaplan, L. M., \& Srivastava, M. B. (2013). On the quality and value of information in sensor networks. ACM Transactions on Sensor Networks, 9(4), 1-26. https://doi.org/10.1145/2489253.2489265

48. Tseng, C. W., Huang, Y. K., Yang, Y. T., Liu, C. C., Huang, D. Y., \& Chou, L. Der. (2017). A network traffic shunt system in SDN network. IEEE CITS 2017 - 2017 International Conference on Computer, Information and Telecommunication Systems, 195-199. https://doi.org/10.1109/CITS.2017.8035281

49. Ferrari, P., \& Sisinni, E. (2017). Evaluation of communication latency in Industrial IoT applications. EEE Internet of Things Journal.

50. Pereira, C., Pinto, A., Ferreira, D., \& Aguiar, A. (2017). Experimental Characterization of Mobile IoT Application Latency. IEEE Internet of Things Journal, 4(4), 1082-1094. https://doi.org/10.1109/JIOT.2017.2689682

51. Staehle, B., Staehle, D., Pries, R., Hirth, M., Dely, P., \& Kassler, A. (2009). Measuring one-way delay in wireless mesh networks: an experimental investigation. Proceedings of the 4th ACM Workshop on Performance Monitoring and Measurement of Heterogeneous Wireless and Wired Networks, 31-38. https://doi.org/10.1145/1641913.1641918

52. Schulz, P., Matthe, M., Klessig, H., Simsek, M., Fettweis, G., Ansari, J., ... Windisch, M. (2017). Latency Critical IoT Applications in 5G: Perspective on the Design of Radio Interface and Network Architecture. IEEE Communications Magazine, 55(2), 70-78. https://doi.org/10.1109/MCOM.2017.1600435CM 
53. Jamal, A. A., \& Teahan, W. J. (2017). Alpha Multipliers Breadth-First Search Technique for Resource Discovery in Unstructured Peer-to-Peer Networks. International Journal on Advanced Science, Engineering and Information Technology, 7(4), 1403-1412. https://doi.org/10.18517/ijaseit.7.4.1451

54. Víctor M. González, José R. Villar2, Enrique de la Cal, Manuel Menéndez, Javier Sedano, Juan Álvarez. IoT and Big Data in well-aging: the IoTEA project. International Journal of Advanced Trends in Computer Science and Engineering. Volume 8, No.1.1, 2019

https://doi.org/10.18517/ijaseit.7.4.1451 